\title{
Effects of the rat blastocyst on neutral lipids and non-specific esterases in the uterine luminal epithelium at the implantation area
}

\author{
D. P. Boshier* \\ Department of Anatomy, University of Auckland, Private Bag, \\ Auckland, New Zealand
}

The close anatomical and physiological relationship between the implanting blastocyst and the associated uterine epithelium was early indicated when Alden (1947) observed that lipid droplets became scarce or wanting in the apical regions of the maternal epithelial cells in the immediate neighbourhood of the rat blastocyst. However, neither Krehbiel (1937) nor Enders \& Schlaf ke (1967) found significant changes in the uterine epithelial lipids, and Potts (1969) stated that at the time of implantation the lipid spread from the basal part of the cell to the supranuclear zone.

After biochemical analyses of whole uterine homogenates, Beall \& Werthessen (1971) concluded that triglycerides, accumulated in the uterine tissues before implantation, were depleted from implantation sites by Day 7. Triglycerides are the principal components of neutral lipids, and these compounds vary in quantity and intracellular distribution within the rat uterine epithelium during the oestrous cycle (Boshier \& Holloway, 1973). The periodic variations in concentrations of neutral lipids result from increased non-specific esterase activity in the uterine epithelium caused by increasing levels of circulating oestrogen (Boshier \& Katz, 1975). This communication reports the results of histochemical investigations of the effect of the blastocyst on neutral lipids and nonspecific esterases in the uterine epithelium at the implantation site.

Mature virgin female rats of a hooded strain were maintained under normal animal house conditions as has been described (Boshier \& Holloway, 1973). After two complete 4-day oestrous cycles, females were caged, usually at the following metoestrus, with males of proven fertility and the day the copulation plug or spermatozoa in the vaginal smear were found was recorded as Day 1 of pregnancy. On the morning of Day $6(128 \mathrm{hr}$ post coitum), $0.5 \mathrm{ml}$ (per $100 \mathrm{~g}$ body wt) of $1 \%$ Pontamine Sky Blue (Gurr's) in sterile injection saline was infused under ether anaesthesia into the jugular vein to assist in localizing the implantation sites (Psychoyos, 1960). Animals were then killed by cervical dislocation and the uterine horns excised and pinned out to their intra-abdominal length under Baker's formol calcium. The uteri were fixed for $24 \mathrm{hr}$ at $4^{\circ} \mathrm{C}$ and then soaked for $24-48 \mathrm{hr}$ in $25 \%$ aqueous sucrose at $4^{\circ} \mathrm{C}$. Preliminary experiments used freshly frozen tissues, but it was found that implantation sites sectioned more easily, stained as intensely, and retained their morphological integrity better after being soaked in the aqueous sucrose.

Transverse sections of the implantation sites and inter-implantation areas were cut at $6-8 \mu \mathrm{m}$ in a microtome cryostat at $-25^{\circ} \mathrm{C}$ and air-dried onto microscope slides. The maternal and embryonic tissues were stained for neutral lipids with Oil Red O (Pearse, 1968) and for esterase activity by the $\alpha$-naphthyl acetate technique of Chayen, Bitensky, Butcher \& Poulter (1969). Ten females, with an average of 8 implantation sites/uterus, were each examined for neutral lipids and esterases.

Between the implantation sites, Oil Red O-positive droplets, indicating the presence of neutral lipids, were present throughout the epithelium, principally in the basal regions and variably in the apical regions of the cells (Pl. 1, Fig. 1). No consistent staining differences were present between the mesometrial and antimesometrial regions of the uterus. The distribution and density of the neutral lipid differed little from that of the pro-oestrous female (Boshier \& Holloway, 1973), but was slightly less than that in the pseudopregnant female at the comparable stage (Boshier, 1974). Esterase activity was also present throughout the luminal epithelium, but was located principally in the apical U.K.

* Present address: Department of Anatomy, University of Cambridge, Downing Street, Cambridge CB2 3DY, 
cytoplasm of the cells (Pl. 1, Fig. 2). Again, no consistent differences in staining density were present between mesometrial and antimesometrial areas although esterases were present throughout the cytoplasm of the glandular epithelial cells. In all implantation sites on the morning of Day 6, all traces of neutral lipids had disappeared from the uterine epithelium in contact with the embryonic trophoblast (PI. 1, Fig. 3). Away from the implantation chamber, the normal epithelial features of variable amounts of supranuclear lipid and dense basal lipid were present (PI. 1, Figs 1 and 3). When agar droplets, as blastocyst analogues, were injected into the uterine lumen of pseudopregnant rats on the morning of Day 5 and left for 19-25 hr, there was no consistent pattern of change in the distribution of the epithelial lipids. The embryonic inner cell mass and trophoblast contained variable amounts of neutral lipid. In some specimens it was absent, in others its density was comparable with that in the epithelium away from the implantation area. Esterase activity was reduced (Pl. 1, Fig. 4) in the epithelium adjacent to the trophoblast, but was comparable with that in the epithelium between the implantation sites (PI. 1, Figs 2 and 4) in the epithelium away from the implanting blastocyst.

These histochemical studies have shown that the implanting rat blastocyst affects lipids in the uterine epithelium adjacent to the trophoblast. Within the limits of the techniques they indicate that intra-epithelial neutral lipids are catabolized during the transition from the irregular-attachment to the smooth-attachment phases described by Ljungkvist \& Nilsson (1971). These authors also noted that, when the smooth-attachment phase was reached, granules of non-specific lipid were reduced in number and were absent altogether soon after. The observations of Alden (1974) are thus partly confirmed, but neither the present findings nor those of Ljungkvist \& Nilsson confirm Potts' (1969) account.

Non-specific esterases, which hydrolyse neutral lipids, are sensitive to the levels of circulating oestrogen. High levels of oestradiol-17 $\beta$ remove neutral lipids from the rat uterine epithelium because they enhance esterase activity (Boshier \& Holloway, 1973; Boshier \& Katz, 1975). Concentrations of oestradiol-17 $\beta$ in ovarian venous blood on Day 5 of pregnancy in rats are low; they then double by Day 6 and reach a maximum on Day 8 (Waynforth, Pope $\&$ Hosking, 1972). It would be consistent with our findings (Boshier \& Katz, 1975) if these rising oestrogen titres stimulated epithelial esterase activity, thus increasing neutral lipid hydrolysis. Such an effect would be followed initially by greater esterase activity which would remove supranuclear lipids to the levels demonstrated (Pl. 1, Figs 1 and 3).

The complete absence of intra-epithelial neutral lipids and diminished esterases at the implantation site suggest an early localized effect mediated by the blastocyst. Smith (1968) has demonstrated that mouse blastocysts can concentrate oestrogen from their culture medium and Perry, Heap \& Amoroso (1973) found that the pig blastocyst is capable of synthesizing oestrogens. In the rat, Dickmann \& Dey (1974) have demonstrated histochemically that $3 \beta$-hydroxysteroid dehydrogenase, an enzyme they consider to indicate steroidogenesis, is present in all blastocysts on the morning of Day 5 of pregnancy, then declines rapidly in significance during Day 6 (Dey \& Dickmann, 1974). Release of oestrogen that was localized in the blastocyst by either sequestration or synthesis during Day 5 would enhance local esterase activity and facilitate epithelial neutral lipid hydrolysis at the implantation site before the rise in ovarian oestradiol-17及 (Waynforth et al., 1972). The effect of the blastocyst on uterine epithelial non-specific esterases during its free and irregular attachment phases should also be examined. Confirmation of the above hypothesis might then be obtained, but this experiment has not yet been undertaken because of the technical difficulties involved.

\section{EXPLANATION OF PLATE 1}

Fig. 1. Neutral lipids in the uterine epithelium between implantation sites in the rat. Oil Red $0, \times 215$.

Fig. 2. Non-specific esterase activity in the uterine epithelium between implantation sites. $\alpha$-Naphthyl acetate as substrate, $\times 86$.

Fig. 3. Implantation site showing loss of neutral lipids in the epithelium adjacent to the trophoblast. Oil Red $0, \times 344$.

Fig. 4. Section showing differences in distribution of esterase activity around the implantation area. $\alpha$-Naphthyl acetate as substrate, $\times 215$. 
PLATE 1
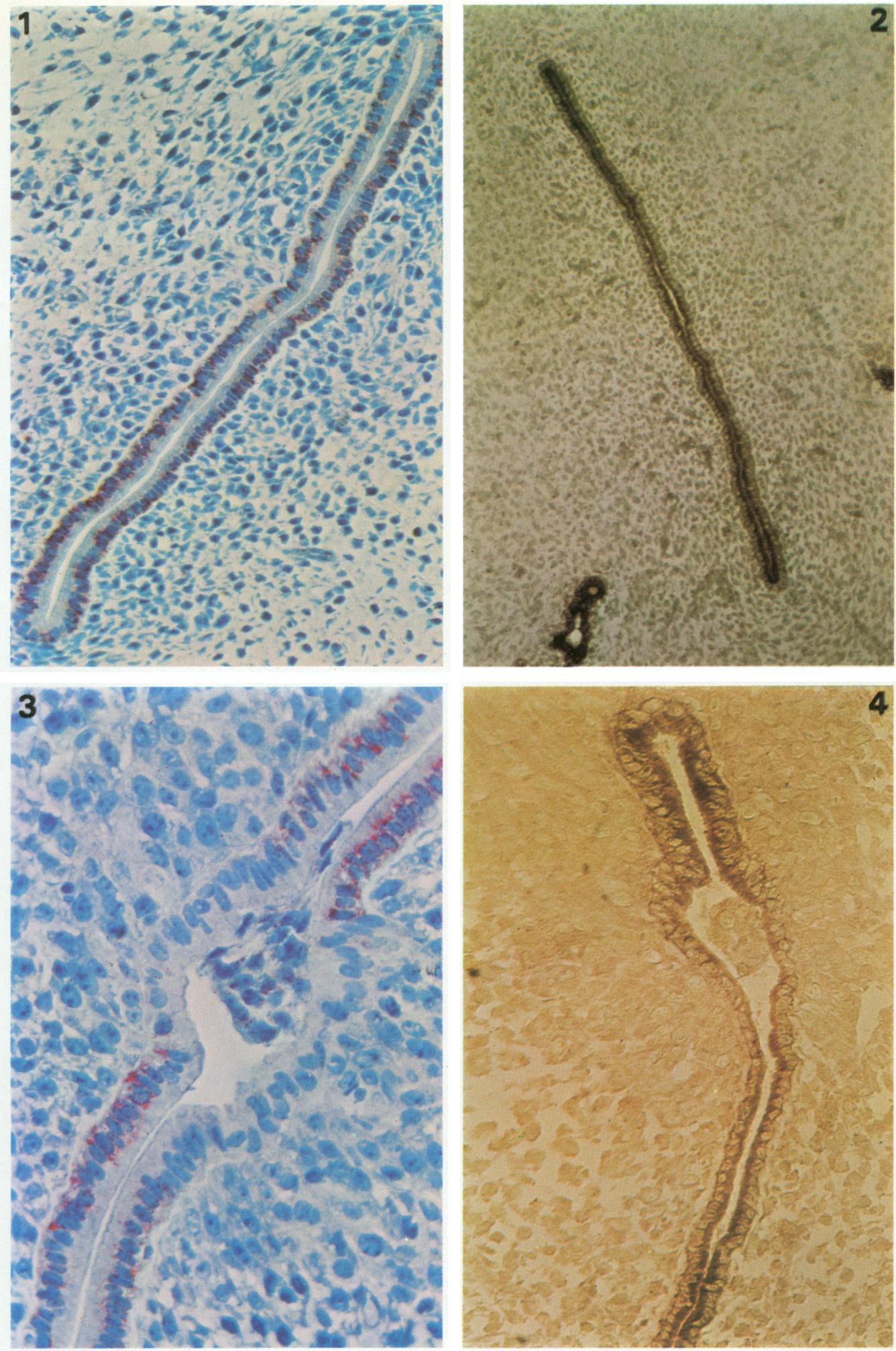

(Facing p. 246) 
During the implantation process, the catabolism of intra-epithelial lipids frees their precursors for metabolism or re-synthesis, possibly by the blastocyst, in which we have found neutral lipids, or by the developing decidua, in which there are also small droplets of neutral lipid (Boshier, 1974). The increasing levels of ovary-derived oestrogens (Waynforth et al., 1972) would similarly facilitate the esterase-mediated hydrolysis of the remainder of the epithelial lipids around the implantation area (see Ljungkvist \& Nilsson, 1971) and permit their use as an energy source during the transformation of the endometrial stroma into the decidua. In this way, both blastocyst-derived and ovarian oestrogens would play important roles during the process of implantation.

The financial support of the Medical Research Council of New Zealand and the skilled technical assistance of Mrs Hilary Holloway, Mrs June Katz, Miss Alison Richards and Mr John Fields is gratefully acknowledged.

\section{References}

Alden, R.H. (1947) Implantation of the rat egg. II. Alterations in epithelial lipids of the rat uterus under normal and experimental conditions. Anat. Rec. 97, $1-19$.

BEALL, J.R. \&WERTHESSEN, N.T. (1971) Lipid metabolism of the rat uterus after mating, J. Endocr.51, 637-644.

BosHIER, D.P. (1974) Neutral lipids in the rat uterine epithelium during pseudopregnancy, the induction of deciduomata and the embryo implantation. $J$. Anat. 118, 388.

Boshier, D.P. \& Holloway, H. (1973) The effects of ovarian steroids on histochemically demonstrable lipids in the rat uterine epithelium. J. Endocr. 56. 5967.

BOSHIER, D.P. \& KATZ, J.M. (1975) Effects of ovarian steroid hormones on esterases in the rat endometrium. J. Endocr. 64, 465-474.

Chayen, J., Bitensky, D., Butcher, R. \& Poulter, L. (1969) A Guide to Practical Histochemistry. Oliver \& Boyd, Edinburgh.

ENDERS, A.C. \& SChLAFKe, S. (1967) A morphological analysis of the early implantation stages in the rat. Am. J. Anat. 120, 185-226.

DEY, S.K. \& DickmanN, Z. (1974) $\Delta^{5}-3 \beta-$ Hydroxysteroid dehydrogenase activity in rat embryos on days 1 through day 7 of pregnancy. Endocrinology 95, 321-322.

Dickmann, Z. \& DEY, S.K. (1974) Steroidogenesis in the preimplantation rat embryo and its possible influence on morula-blastocyst transformation and implantation. J. Reprod. Fert. 37, 91-93.

KREHBIEL, R.H. (1937) Cytological studies of the decidual reaction in the rat during early pregnancy and in the production of deciduomata. Physiol. Zoöl. 10, 212-223.

LJUNGKvist, I. \& Nilsson, O. (1971). Ultrastructure of rat uterine luminal epithelium at functional states compatible with implantation. Z. Anat. EntwGesch. 135, 101-107.

Pearse, A.G.E. (1968) Histochemistry: Theoretical and Applied, 3rd edn, Vol. 1. Churchill, London.

Perry, J.S., Heap, R.B. \& Amoroso, E.C. (1973) Steroid hormone production by pig embryos. Nature, Lond. 245, 45-47.

Porrs, M. (1969) The ultrastructure of egg implantation. Adv. Reprod. Physiol. 4, 241-267.

Psychoyos, A. (1960) La réaction déciduale est précédée de modifications précoses de la perméabilite capillaire de l'utérus. C. r. Séanc. Soc. Biol. 154, 13841387.

Sмiтн, D.M. (1968) The effect on implantation of treating cultured mouse blastocysts with oestrogen in vitro and the uptake of $\left[{ }^{3} \mathrm{H}\right]$ oestradiol by blastocysts. J. Endocr. 41, 17-29.

WAYNForth, H.B., PoPe, G.S. \& Hosking, Z.D. (1972) Secretion rates of oestrogens into the ovarian venous blood of pregnant rats. J. Reprod. Fert. 28 , 191-196.

Received 3 June 1975 